\title{
A Current-mode Electronically Controllable Multifunction Biquadratic Filter Using CCCIIs
}

\author{
S. Srisakultiew ${ }^{1}$, S. Lawanwisut ${ }^{2}$ and M. Siripruchyanun ${ }^{3}$
}

\begin{abstract}
This article presents a current-mode multifunction biquadratic filter performing completely standard functions low-pass, high-pass, band-pass, band-reject and all-pass functions. The circuit principle is based on secondgeneration current-controlled current conveyor (CCCII) with three input terminals and one output terminal. The features of the circuit are that, the pole frequency can be tuned via the bias currents. The circuit topology is very simple, consisting of merely 2 CCCIIs and 2 grounded capacitors. Without any external resistor and using only grounded elements, the proposed circuit is very comfortable to further develop into an integrated circuit architecture. The PSpice simulation results are shown. The given results agree well with the theoretical anticipation. The total power consumption is approximately $1.87 \mathrm{~mW}$ at $\pm 1.5 \mathrm{~V}$ power supply voltages.
\end{abstract}

Keywords - Current-mode, Biquadratic filter, CCCII.

\section{INTRODUCTION}

An analog filter is an important building block, widely used for continuous-time signal processing. It can be found in many fields: including, communications, measurement, and instrumentation, and control systems [1-2]. One of most popular analog filters are multi-purpose and universal filters that can be classified either as multi-input and single-output (MISO) filter [3] or single-input and multi-output (SIMO) filter [4]. The MISO current-mode filters have rather simple structures [5]. Recently, a multifunction filter working in current-mode has being been more popular than the voltagemode type. Since the last two decades, there has been much effort to reduce the supply voltage of analog systems. This is due to the demand for portable and battery-powered equipment. Since a low-voltage operating circuit becomes necessary, the current-mode technique is ideally suited for this purpose. Actually, a circuit using the current-mode technique has many other advantages, such as, larger dynamic range, higher bandwidth, greater linearity, simpler circuitry and lower power consumption [6-7].

A second generation current conveyor (CCII) is a reported active component, especially suitable for a class of analog signal processing [8]. The fact that the device can operate in both current and voltage-modes provides

Manuscript received October 20, 2012, revised January 18, 2013.

S. Srisakultiew ${ }^{I}$ Computer Engineering, Faculty of Engineering and Architecture, Rajamangala University of Technology Isan, 744 Suranarai Rd. Nai-Maung, Maung, Nakhonratsima, 30000, Thailand (e-mail: somchaikorat2008@hotmail.com)

S. Lawanwisut ${ }^{2}$ Dept. of Information and Communication Engineering, Faculty of Industrial Technology, Thepsatri Rajabhat University, Lopburi, 15000, Thailand (e-mail: s.lawanpisut@hotmail.com)

M. Siripruchyanun ${ }^{3}$ Dept. of Teacher Training in Electrical Engineering, Faculty of Technical Education, King Mongkut's University of Technology North Bangkok, Bangsue, Bangkok, 10800, Thailand (e-mail mts@kmutnb.ac.th) flexibility and enables a variety of circuit designs. In addition, it can offer advantageous features such as high slew-rate, high-speed, wide bandwidth and simple implementation [8-9]. However, the parasitic resistance at $X$ $\left(R_{x}\right)$ port cannot be controlled so when it is used in some circuits, it unavoidably requires some external passive components, especially the resistors. This makes it not appropriate for IC implementation due to occupying more chip area, consuming high power and without electronic controllability. On the other hand, the introduced secondgeneration current-controlled conveyor (CCCII) [10] has the advantage of electronic adjustability over the CCII. Also, the use of multiple-output current conveyors is found to be useful in the derivation of current-mode single-input threeoutput filters using a reduced number of active components [11-12].

From our survey, it is found that several implementations of current-mode multifunction biquadratic filters have been reported [13-33]. Unfortunately, these reported circuits suffer from one or more of following weaknesses:

- Excessive use of the passive elements, especially the external resistors [15-17, 19, 23-26, 28-33].

- Lack of electronic adjustability [15-17, 19, 23-26, 2832].

- Require changing circuit topologies to achieve several functions [14-16, 20-21, 24-26].

- Some outputs of the filter responses are not in high output impedance [13-14, 15, 17-18].

- Cannot provide completely standard function [19-20, $22,24-25,28-29,31]$

The aim of this paper is to propose a current-mode multifunction biquadratic filter, emphasizing on use of the CCCIIs and grounded capacitors. The features of the proposed circuit are that, the proposed multifunction biquadratic filter can completely provide 5 functions which are low-pass high-pass band-pass band-reject and all-pass, without changing circuit topology, the circuit description is very simple, employing only grounded capacitors as passive components, thus it is suitable for fabricating in monolithic chip. The quality factor and pole frequency can be electronically adjusted. The PSpice simulation results are also shown, which are in correspondence with the theoretical analysis.

\section{PRINCIPLE OF OPERATION}

\section{A. Multiple-output Current Controlled Current Conveyor (MO-CCCII)}

Since the proposed circuit is based on MO-CCCII, it will be introduced in this section. Typically, the MO-CCCII is a 
versatile analog building block which including 3-ports, $\mathrm{x}, \mathrm{y}$ and $\mathrm{z}$. The matrix-relationship between voltage and current are variables among port $x, y$ and $z$ of ideal following matrix equation in Eq. (1). Where the positive and negative signs of the current $i_{z}$ denote the positive (CCCII+) and negative (CCCII-), respectively, and $R_{x}$ is an intrinsic resistance of CCCII. The X-terminal resistance is calculated by Eq. (2) and $V_{T}$ is the thermal voltage. Fig.1 (a) and (b) illustrates the symbol and equivalent circuit, respectively.

$$
\left[\begin{array}{c}
i_{y} \\
v_{x} \\
i_{z}
\end{array}\right]=\left[\begin{array}{ccc}
0 & 0 & 0 \\
1 & R_{x} & 0 \\
0 & \pm 1 & 0
\end{array}\right]\left[\begin{array}{c}
v_{y} \\
i_{x} \\
v_{z}
\end{array}\right]
$$

where

$$
R_{x}=\frac{V_{T}}{2 I_{B}}
$$

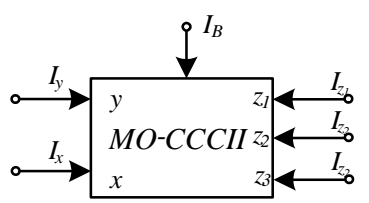

(a)

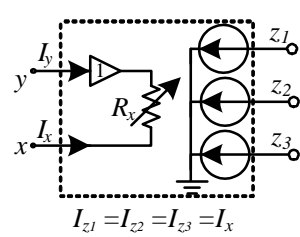

(b)
Fig. 1. MO-CCCII (a) Symbol, (b) Equivalent circuit.

\section{B. Implementation of the filter}

The proposed filter is designed by cascading summing currents and the current-mode lossless integrator as systematically shown in Fig. 2. From block diagram in Fig. 2, its transfer function can be found to be [34-36]

$$
I_{\text {out }}=\frac{\left(s^{2}+s b+a b\right) I_{i n 3}+s b I_{i n 2}+a b I_{i n 1}}{s^{2}+s b+a b} .
$$

From Eq. (3), the pole frequency $\left(\omega_{0}\right)$ and quality factor $\left(Q_{0}\right)$ of each filter response can be expressed as

$$
\omega_{o}=\sqrt{a b}
$$

and

$$
Q_{o}=\sqrt{\frac{a}{b}}
$$

It is found that the pole frequency and the quality factor can be adjusted by either $a$ or $b$.

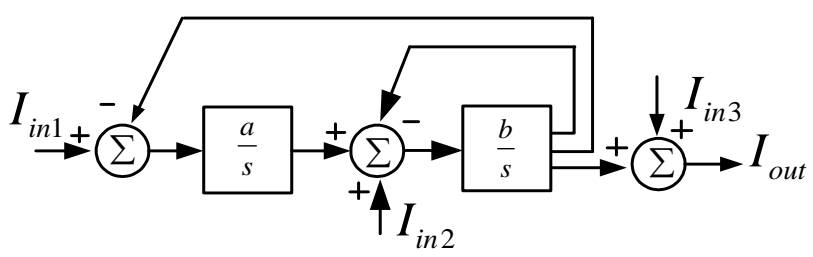

Fig 2. Block diagram for filter implementation [34].
C. Proposed current-mode multifunction biquadratic filter The filter is designed by cascading the lossless integrators as systematically shown in Fig. 3. From circuit in Fig. 3, the current transfer function can be expressed as

$$
\frac{I_{\text {out }}}{I_{\text {in }}}=\frac{1}{s \tau},
$$

where $\quad \tau=\frac{2 I_{B}}{C V_{T}}$

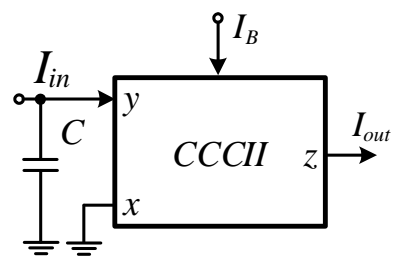

Fig. 3. Lossless integrator using CCCII

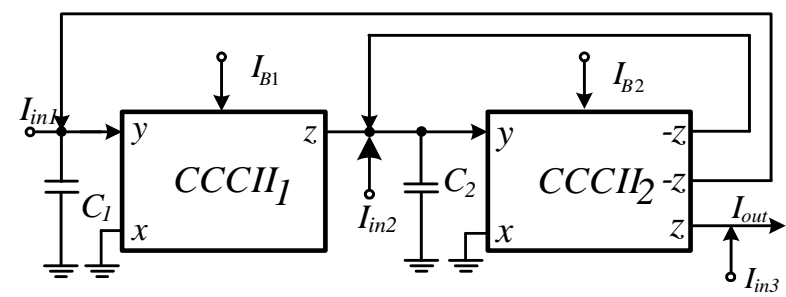

Fig. 4. Proposed current-mode multifunction biquadratic filter.

The complete current-mode multifunction biquadratic filter is shown in Fig. 4. From Eq. (7), the output current of the circuit in Fig. 4 can be obtained as

$$
I_{\text {out }}=\frac{\left(s^{2}+\frac{s}{C_{2} R_{x 2}}+\frac{1}{R_{x 1} R_{x 2} C_{1} C_{2}}\right) I_{\text {in } 3}+\frac{s}{C_{2} R_{x 2}} I_{i n 2}+\frac{1}{R_{x 1} R_{x 2} C_{1} C_{2}} I_{i n 1}}{s^{2}+\frac{s}{C_{2} R_{x 2}}+\frac{1}{R_{x 1} R_{x 2} C_{1} C_{2}}} .
$$

From Eq. (7), the all standard transfer functions can be obtained by selecting appropriate inputs by following conditions

1) If $I_{i n}=I_{i n 1}$, and $I_{i n 2}=I_{i n 3}=0$, a low-pass function is achieved at the output. The transfer function can be written to be

$$
\frac{I_{\text {out }}}{I_{\text {in }}}=\frac{\frac{1}{R_{x 1} R_{x 2} C_{1} C_{2}}}{s^{2}+\frac{s}{C_{2} R_{x 2}}+\frac{1}{R_{x 1} R_{x 2} C_{1} C_{2}}} .
$$

2) If $I_{i n}=-I_{i n 1}=-I_{i n 2}=I_{i n 3}$, a high-pass function can be obtained. The transfer function can be written to be

$$
\frac{I_{\text {out }}}{I_{\text {in }}}=\frac{s^{2}}{s^{2}+\frac{s}{C_{2} R_{x 2}}+\frac{1}{R_{x 1} R_{x 2} C_{1} C_{2}}} .
$$


3) If $I_{i n}=I_{i n 2}$, and $I_{i n 1}=I_{i n 3}=0$, the obtained output function is a band-pass. The transfer function can be given by

$$
\frac{I_{\text {out }}}{I_{\text {in }}}=\frac{\frac{s}{C_{2} R_{x 2}}}{s^{2}+\frac{s}{C_{2} R_{x 2}}+\frac{1}{R_{x 1} R_{x 2} C_{1} C_{2}}} .
$$

4) If $I_{i n}=I_{i n 3}=-I_{i n 2}$, and $I_{i n 1}=0$, a band-reject function is provided. The transfer function can be written to be

$$
\frac{I_{\text {out }}}{I_{\text {in }}}=\frac{s^{2}+\frac{1}{R_{x 1} R_{x 2} C_{1} C_{2}}}{s^{2}+\frac{s}{C_{2} R_{x 2}}+\frac{1}{R_{x 1} R_{x 2} C_{1} C_{2}}}
$$

5) If $I_{i n}=I_{i n 3}=-2 I_{i n 2}$, and $I_{i n 1}=0$, an all-pass filter is obtained. The transfer functions can be written to be

$$
\frac{I_{\text {out }}}{I_{\text {in }}}=\frac{s^{2}-\frac{s}{C_{2} R_{x 2}}+\frac{1}{s^{2}+\frac{s}{C_{x 1} R_{x 2} C_{1} C_{2}}}+\frac{1}{R_{x 2} R_{x 2} C_{1} C_{2}}}{.}
$$

The selection to obtain each function can be achieved by digital method, the digital selection circuit can be found in [37].

The pole frequency $\left(\omega_{0}\right)$ and quality factor $\left(Q_{0}\right)$ can be expressed to be

$$
\omega_{0}=\frac{1}{\sqrt{C_{1} C_{2} R_{x 2} R_{x 3}}}
$$

and

$$
Q_{0}=\sqrt{\frac{C_{1} R_{x 2}}{C_{2} R_{x 3}}},
$$

where $\quad R_{x 1}=\frac{V_{T}}{2 I_{B 1}}, \quad R_{x 2}=\frac{V_{T}}{2 I_{B 2}}$. Thus, we get

$$
\omega_{0}=\frac{2}{V_{T}} \sqrt{\frac{I_{B 1} I_{B 2}}{C_{1} C_{2}}},
$$

and

$$
Q_{0}=\sqrt{\frac{C_{1} I_{B 2}}{C_{2} I_{B 1}}} .
$$

From Eqs. (15) and (16), the pole frequency can be electronically controlled, which is independent from the quality factor by varying $I_{B 1}$ and $I_{B 2}$ (keeping their ratio constant). Furthermore, bandwidth of the system can be expressed by

$$
B W=\frac{\omega_{0}}{Q_{0}}=\frac{2 I_{B 1}}{V_{T} C_{1}} .
$$

We found that the bandwidth can be linearly controlled by $I_{B 1}$.

\section{Sensitivity analysis}

The sensitivities of the proposed filter can be found to be:

$$
\begin{array}{ll}
S_{C_{1}, C_{2}}^{\omega_{0}}=-\frac{1}{2}, & S_{I_{B 1}, I_{B 2}}^{\omega_{0}}=\frac{1}{2}, \\
S_{I_{B 2}, C_{1}}^{Q_{0}}=\frac{1}{2}, & S_{I_{B 1}, C_{1}}^{Q_{0}}=-\frac{1}{2} .
\end{array}
$$

and

$$
S_{V_{T}, C_{2}}^{B W}=-1, \quad S_{I_{B 1}}^{B W}=1
$$

Therefore, all active and passive sensitivities are equal or less than unity in magnitude.

\section{E. Non-ideal Case}

For non-ideal case, the voltage and current tracking errors of the MO-CCCII effect on the performance of the proposed filter. By routine analysis, the MO-CCCII with non-ideal case can be respectively characterized with the following equations

$$
I_{y}=0, V_{x}=\beta V_{y}+R_{x} I_{x}, I_{z}=\alpha I_{x},
$$

$\beta=1-\varepsilon_{\mathrm{V}}\left(\varepsilon_{\mathrm{V}}<<1\right)$ is the voltage gain, where $\varepsilon_{\mathrm{V}}$ is the voltage tracking error from $\mathrm{V}_{\mathrm{y}}$ to $\mathrm{V}_{\mathrm{x}}$ of MO-CCCII. $\alpha$ is the current gain equal to $1-\varepsilon_{\mathrm{i}}\left(\varepsilon_{\mathrm{i}}<<1\right)$, where $\varepsilon_{\mathrm{i}}$ is the output current tracking error of MO-CCCII. In the case of non-ideal and reanalysis of proposed filter circuit in Fig. 4, it yields the output current as

$$
I_{\text {out }}=\frac{\left(s^{2}+\frac{s \alpha_{2} \beta_{2}}{C_{2} R_{x 2}}+\frac{\alpha_{1} \alpha_{2} \beta_{1} \beta_{2}}{R_{x 1} R_{x 2} C_{1} C_{2}}\right) I_{i n 3}+\frac{s \alpha_{2} \beta_{1}}{C_{2} R_{x 2}} I_{i n 2}+\frac{\alpha_{1} \alpha_{2} \beta_{1} \beta_{2}}{R_{x 1} R_{x 2} C_{1} C_{2}} I_{i n 1}}{s^{2}+\frac{s \alpha_{2} \beta_{2}}{C_{2} R_{x 2}}+\frac{\alpha_{1} \alpha_{2} \beta_{1} \beta_{2}}{R_{x 1} R_{x 2} C_{1} C_{2}}},
$$

In this case, the $\omega_{0}$ and $Q_{0}$ are changed to

$$
\omega_{0}=\sqrt{\frac{\alpha_{1} \alpha_{2} \beta_{1} \beta_{2}}{C_{1} C_{2} R_{x 1} R_{x 2}}}
$$

and

$$
Q_{0}=\sqrt{\frac{\alpha_{2} \beta_{2} C_{1} R_{x 1}}{\alpha_{1} \beta_{1} C_{2} R_{x 2}}},
$$

while BW is still equal to Eq. (17). These errors affect the sensitivity to temperature and high frequency response of the proposed circuit, then the MO-CCCII should be designed to achieve these errors as low as possible, for example, using a high performance current mirror. Consequently, these deviations are very small and can be ignored. 


\section{Simulation Results}

To prove and investigate the performances of the proposed circuit, the PSpice simulation program was used for the examination. The PNP and NPN transistors employed in the CCCIIs were simulated by respectively using the parameters of the PR200N and NR200N bipolar transistors of ALA 400 transistor array from AT\&T [38]. Fig. 5 depicts schematic description of the CCCII used in the simulations. The circuit was biased with $\pm 1.5 \mathrm{~V}$ power supplies voltage, $C_{l}=C_{2}=\ln F$, $I_{B I}=I_{B 2}=50 \mu \mathrm{A}$. The results shown in Fig. 6 are the gain responses of the proposed multifunction biquadratic filter. It is clearly seen that it can provide low-pass high-pass bandpass band-reject and all-pass functions dependent on selection as depicted in Eqs. (8)-(12). Fig. 7 shows gain responses of band-pass function, where $I_{B 1}$ and $I_{B 2}$ are equally set to keep the ratio to be constant and changed for several values. It is found that pole frequency can be adjusted without affecting the quality factor as analyzed in Eqs. (15)-(16). Fig. 8 shows gain responses of band-pass function where $I_{B I}$ is set for several values. It is found that pole frequency can be adjusted electronically. Fig. 9 shows evaluated pole frequency compared with simulation result. The transient and spectrum responses of the proposed filter from band-pass function for center frequency of $547.293 \mathrm{kHz}$ can be seen in Fig. 10 and 11, respectively, where THD is $0.227 \%$. Total power consumption obtained from PSpice is about $1.87 \mathrm{~mW}$.

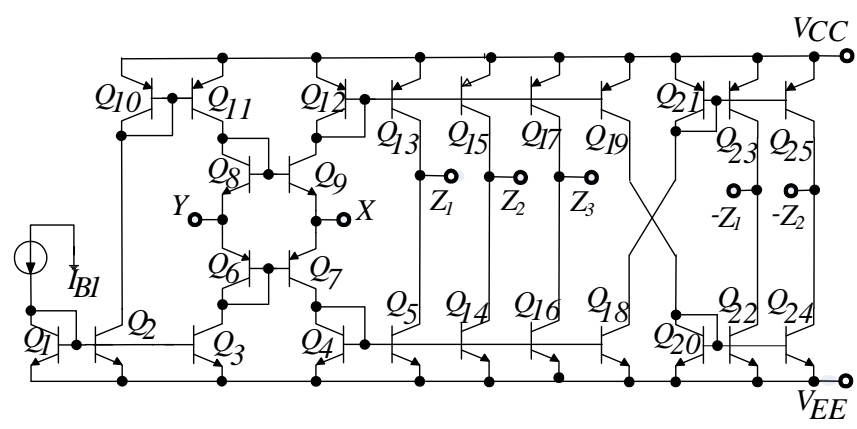

Fig. 5. Internal construction of MO-CCCII.

\section{CONCLUSION}

The current-mode multifunction biquadratic filter with three input terminals and one output terminal based on CCCII has been presented. The advantages of the proposed circuit are that, it performs completely standard functions, which are low-pass high-pass band-pass band-reject and all-pass functions from the same circuit configuration, without component matching conditions and changing circuit topology. The pole frequency can be electronically adjusted without affecting the quality factor. The circuit description comprises only 2 MO-CCCIIs and 2 grounded capacitors. With mentioned features, it is very suitable to realize the proposed circuit in monolithic chip to use in batterypowered, portable electronic equipment such as wireless communication system.

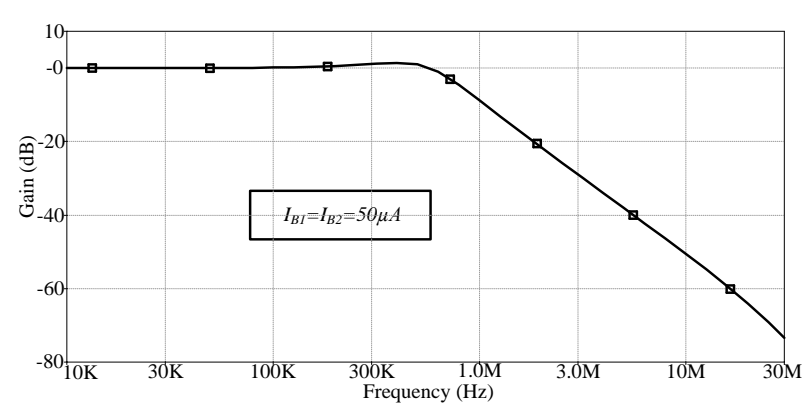

(a)

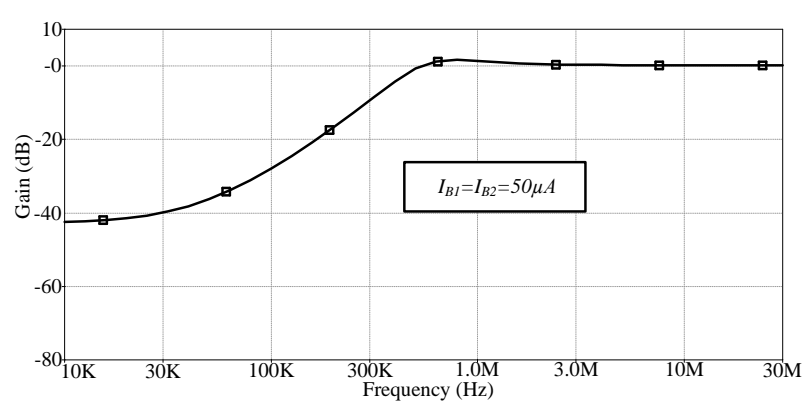

(b)

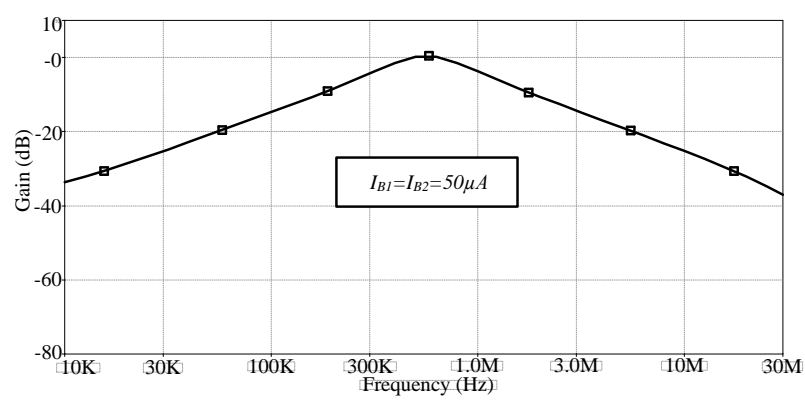

(c)

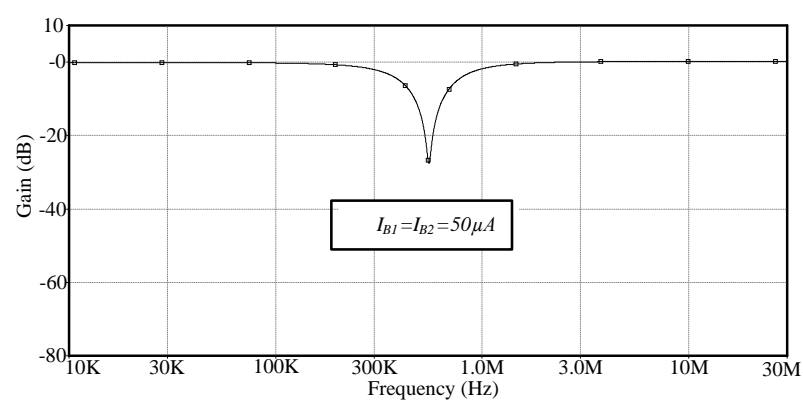

(d)

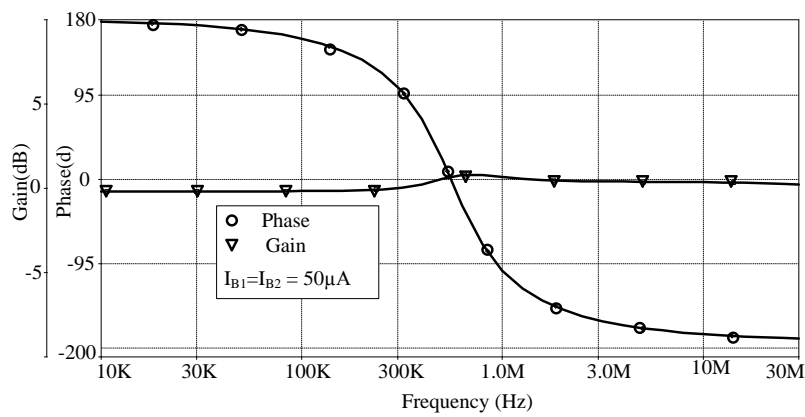

(e)

Fig. 6. Gain responses of the biquadratic filter (a) LP (b) HP (c) BP (d) BR (e) AP. 


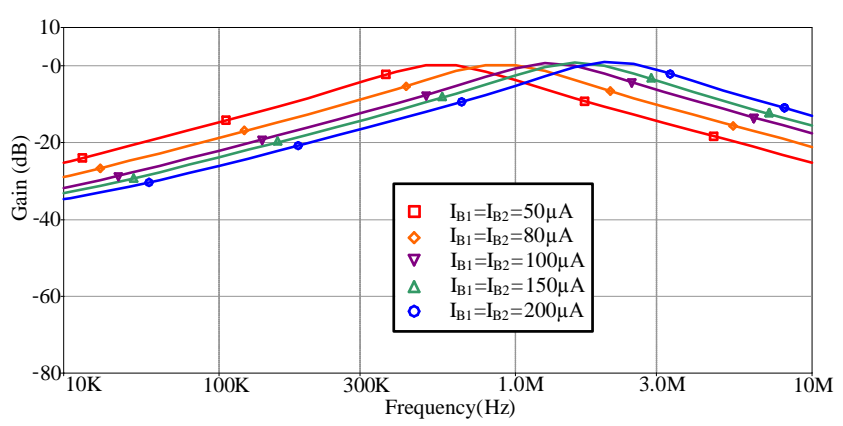

Fig 7. Band-pass responses for different values of $I_{B 1}$ and $I_{B 2}$ with keeping their ratios constant.

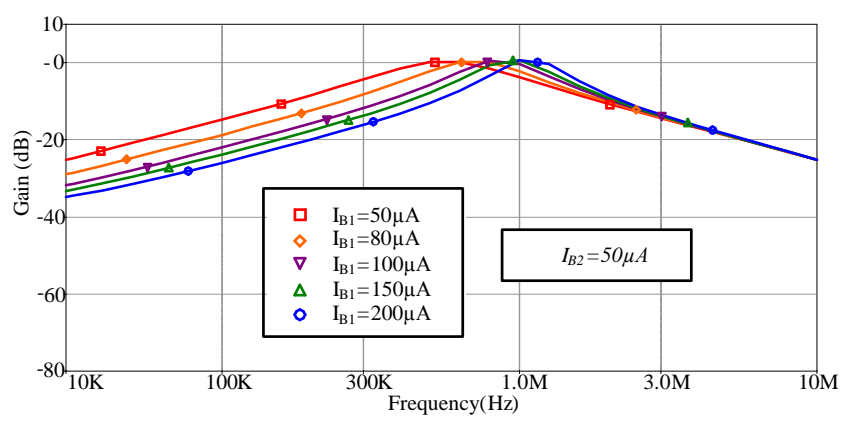

Fig 8. Current-mode bandpass responses for different values of $I_{B I}$

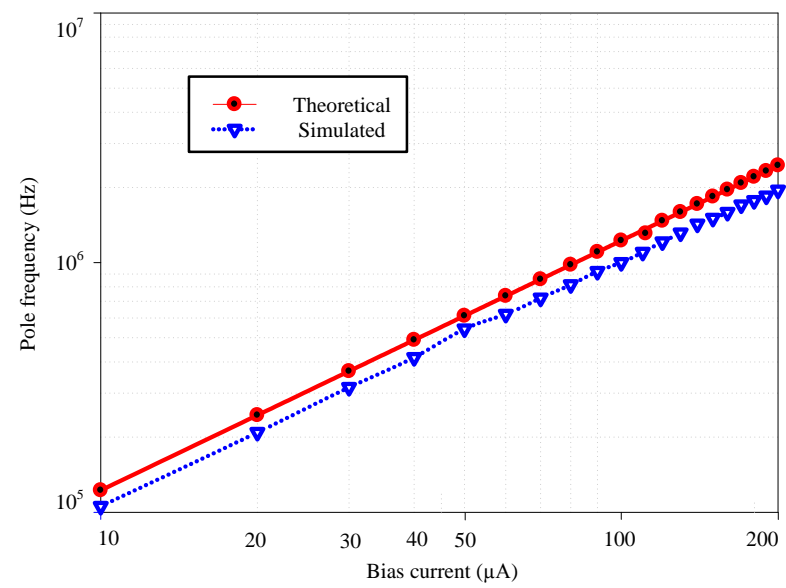

Fig 9. Deviation of the calculated pole frequency compared with the simulated value.

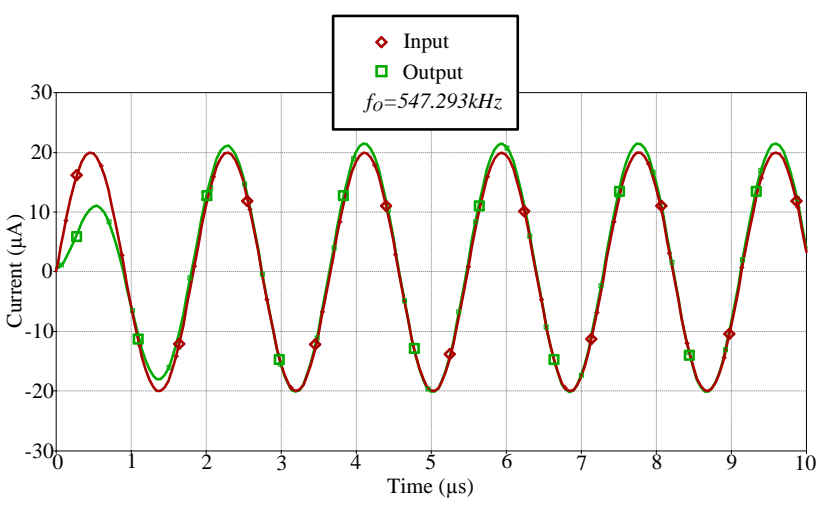

Fig 10. Transient responses at center frequency of $547.293 \mathrm{kHz}$ obtained from the proposed filter for BP function.

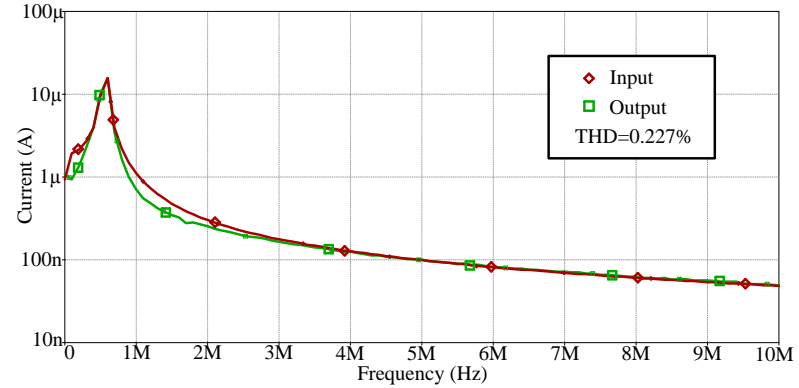

Fig. 11. Frequency spectrum of obtained signal in Fig. 10.

\section{REFERENCES}

[1] A. S. Sedra, and K. C. Smith, Microelectronic circuits, 5rd ed., Florida: Holt, Rinehart and Winston, 2003.

[2] M. A. Ibrahim, S. Minaei, and H.A. Kuntman, “A 22.5 MHz currentmode KHN-biquad using differential voltage current conveyor and grounded passive elements," International Journal of Electronics and Communications (AEU), vol. 59, pp. 311-318, 2005.

[3] W. Chunhua, L. Haiguang, and Z. Yan, "Universal current-mode filter with multiple inputs and one output using MOCCII and MOCCCA," International Journal of Electronics and Communications (AEU), vol. 63, no. 6, pp. 448-453, 2009.

[4] S. Minaei, H. Kuntman, O. Cicekoglu, S. Turkoz and N. Tarim, “A new high output impedance current-mode universal filter with single input and three outputs using dual output CCIIs," Proceedings of the 7th IEEE International Conference on Electronics, Circuits and Systems, vol. 1, pp. 379-382, 2000.

[5] W. Chumhua, Z. Yan, Z. Qiujing and D. Sichun, "A new current mode SIMO-type universal biquad employing multi-output current conveyors (MOCCII)," Radioengineering, vol 18, no. 1, pp. 83-88, 2009.

[6] C. Toumazou, F. J. Lidgey, and D. G. Haigh, “Analogue IC design: the current-mode approach," Peter Peregrinus, London, 1990.

[7] D. R. Bhaskar, V. K. Sharma, M. Monis, and S. M. I. Rizvi, "New current-mode universal biquad filter," Microelectronics Journal, vol. 30, pp. 837-839, 1999.

[8] K. C. Smith and A. Sedra, "The current conveyor-a new circuit building block,” IEEE Proc. vol. 56, pp. 1368-1369, 1968.

[9] A. Sedra and K. C. Smith, "A second-generation current conveyor and its applications," IEEE Trans. Circuit Theory, vol. 17, pp. 132134, 1970.

[10] A. Fabre, O. Saaid, F. Wiest, and C. Boucheron, "Current controllable bandpass filter based on translinear conveyors," Electronics Letters, vol. 31, pp. 1727-1728, 1995.

[11] K. Ikeda and Y. Tomita, "Realization of current-mode biquadratic filter using CCIIs with current followers," Electronics and Communications in Japan, part 2, vol. 77, pp. 99-107, 1994.

[12] A. M. Soliman, "New current-mode filters using current conveyors," International Journal of Electronics and Communications (AEU), vol. 51, pp. 275-278, 1997.

[13] S. Ozoguz, A. Toker, and C. Acar. "Current-mode continuous-time fully-integrated universal filter using CDBAs," Electronics Letters, vol. 35, pp. 97-98, 1999.

[14] S. Maheshwari, and I.A. Khan, "Current-controlled current differencing buffered amplifier: implementation and applications," Active and Passive Electronic Components, vol. 27, pp. 219-227, 2004.

[15] S. Kilinc, and U. Cam, "Current differencing buffered amplifier (CDBA) based current-mode filters," Proceedings of the IEEE 12th Signal Processing and Communications Applications, Cesme, Turkey, pp. 634-637, 2004.

[16] A. Toker, S. Ozoguz, O. Cicekoglu, and C. Acar, "Current-mode allpass filters using current differencing buffered amplifier and a new high-Q bandpass filter configuration," IEEE Transactions on Circuits 
and Systems II-Analog and Digital Signal Processing, vol. 47, pp. 949-954, 2000.

[17] S. Ozoguz, A. Toker, and C. Acar, "Cascadable current mode multipurpose filters employing current differencing buffered amplifier (CDBA)," International Journal of Electronics and Communications (AEU), vol. 56, pp. 67-72, 2000.

[18] W. Jaikla, K. Sooksood, M. Siripruchyanun, "Current controlled CDBAs, (CCCDBAs)-based novel current-mode universal biquadratic filter," Proceedings of the 2006 IEEE International Symposium on Circuits and Systems (ISCAS 2006), Kos, Greece, pp. 3806-3809, 2006.

[19] N. A. Shah and M. A. Malik, "Multifunction mixed-mode filter using FTFNs," Analog ICs and Signal Processing, vol. 47, pp. 339343, 2006.

[20] J. WU and E. I. EL-Masry, "Universal voltage- and current-mode OTAs based biquads," International Journal of Electronics, vol.85, pp. 553-560, 1998.

[21] ] D. R. Bhaskar, R. K. Sharma, A. K. Singh, and R. Senani, "New dual-mode Biquads Using OTAs," Frequenz, vol. 60, pp. 246-252, 2006.

[22] D. R. Bhaskar, A. K. Singh, R. K. Sharma and R. Senani, "New OTA-C universal current-mode/trans-admittance biquads," IEICE Electronics Express, vol. 2, pp.8-13, 2005.

[23] N. Pandey, S. K. Paul, A. Bhattacharyya and S. B. Jain, "A new mixed mode biquad using reduced number of active and passive elements," IEICE Electronics Express, vol. 3, pp.115-121, 2006.

[24] C. L. Hou, C. C. Huang, Y. S. Lan, J. J. Shaw and C. M. Chang, "Current-mode and voltage-mode universal biquads using a single current-feedback amplifier," International Journal of Electronics, vol. 86, pp. 929-932, 1999.

[25] N. A. Shah and M. A. Malik, "Voltage/current-mode universal filter using FTFN and CFA," Analog ICs and Signal Processing, vol. 45, pp. 197-203, 2005.

[26] S. T. Liu and J. L. Lee, "Insensitive current/voltage-mode filters using FTFNs," Electronics Letters, vol. 32, pp.1079-1080, 1996

[27] N. A. Shah and M. A. Malik, "Multifunction mixed-mode filter using FTFNs," Analog ICs and Signal Processing, vol. 47, pp. 339343, 2006.

[28] N. A. Shah S. Z. Iqbal and B. Parveen, "SITO high output impedance transadmittance filter using FTFNs," Analog ICs and Signal Processing, vol. 40, pp. 87-89, 2004.

[29] C. L. Hou and C. C. Lin, "A filter with three voltage-inputs and one voltage-output and one current-output using current Conveyors," Tamkang Journal of Science and Engineering, vol. 7, pp. 145-148, 2004.

[30] N. Pandey, S. K. Paul, A. Bhattacharyya and S. B. Jain, "A new mixed mode biquad using reduced number of active and passive elements," IEICE Electronics Express, vol. 3, pp.115-121, 2006.

[31] A. Toker, O. Cicekoglu, S. Ozoguz and H. Kuntman, "High output impedance transadmittance type continuous time multifunction filter with minimum active elements," International Journal of Electronics, vol.88, pp. 1085-1091, 2001.

[32] M. T. Abuelma' atti and A. Bentrcia, "A novel mixed-mode CCIIbased filter," Active and Passive Electronic Components, vol. 27, pp. 197-205, 2004.

[33] M. T. Abuelma'atti, "A novel mixed-mode current-controlled current conveyor-based filter," Active and Passive Electronic Components, vol. 26, pp. 185-191, 2003.

[34] S. Lawanwisut, and M. Siripruchyanun, "Active-only electronically controllable current-mode multifunction biquadratic filter using CCCCTA," Electrical Engineering Conference 33, vol. 2, pp. 1097 1100,2010

[35] Y. Sun, and B. Jefferies, "Current-mode biquadratic filters using dual output current conveyors", IEEE Int. Conf. Electronics, Circuits and Systems, vol. 3, pp. 135-138, 1998.
[36] M. Kumgern, P. Moungnoul, S. Junnapiya, and K. Dejhan, "Currentmode universal filter using translinear current conveyors", Int. Conf. Elect. Eng./Electr., Comp., Telecom., Inf. Tech., pp. 717-720, 2008.

[37] Y. Maruyama, A. Hyogo, and K. Sekine, "A digitally programmable CMOS biquad filter using current-mode integrators," IEICE trans. on fundamentals, vol. E85-A, no. 2, pp. 316-323, 2002

[38] D.R. Frey, "Log-domain filtering: an approach to current-mode filtering," IEE Proceeding of Circuit Devices Systems, vol. 140, pp 406-416, 1993.

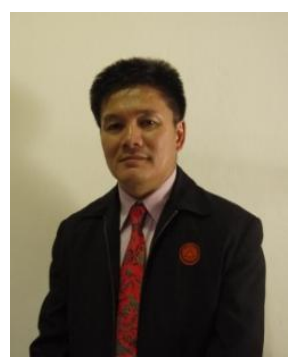

Somchai Srisakultiew received the B. Tech. Ed. in telecommunication engineering. and M.Tech electrical communication engineering degree in from King Mongkut's Institute of Technology Ladkrabang, Thailand in 1985 and 2002, B.Eng Master of Tech. Ed. in electrical technology from Rajamangala Institute of Technology Thunyaburi, Pha-thumthani in 2003. He has been with Computer Engineering, Faculty of Engineering and Architecture, Rajamangala University of Technology Isan, 744 Suranarai Rd. Nai-Maung, Maung, Nakhonratsima, 30000, Thailand since 1986. His research interests include electronic communications, analog signal processing and analog integrated circuit. He is a member of ECTI (Thailand).

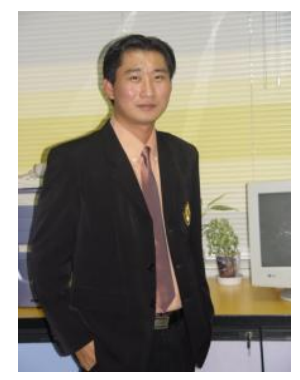

Supawat Lawanwisut was born in Petchaburi, Thailand in 1975. He received the B. Tech. Ed. degree in electronic and computer and $\mathrm{M}$. Tech. Ed. in electrical communication engineering from King Mongkut's Institute of Technology Ladkrabang, Thailand in 1996 and 2001, B. Eng. in electrical engineering from Thonburi University Thailand in 2011, respectively. He has been with department of Information and Communication Engineering, Faculty of Industrial Technology, Thepsatri Rajabhat University, Lopburi, Thailand since 2002. His research interests include electronic communications, analog signal processing and analog integrated circuit.

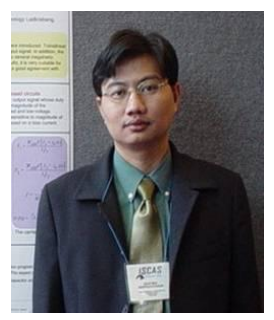

Montree Siripruchyanun received the B. Tech. Ed. degree in electrical engineering from King Mongkut's Institute of Technology North Bangkok (KMITNB), the M.Eng. and D. Eng. degree both in electrical engineering from King Mongkut's Institute of Technology Ladkrabang (KMITL), Bangkok, Thailand, in 1994, 2000 and 2004, respectively. He has been with Faculty of Technical Education, KMITNB since 1994. Presently, he is with Department of Teacher Training in Electrical Engineering as an Associate Professor, KMITNB. His research interests include analog-digital communications, analog signal processing and analog integrated circuit. He is a member of IEEE (USA), IEICE (Japan), and ECTI (Thailand). 